\title{
Perception of male and female personality attributes and behaviors by Dutch children
}

\author{
VANDA L. ZAMMUNER \\ University of Padua, Padua, Italy
}

\begin{abstract}
Qualitative and quantitative aspects of children's knowledge of sex-role stereotypes were investigated using two sets of 28 stimuli, descriptive of behaviors and personality attributes. Two hundred nineteen Dutch 10- and 12-year-old boys and girls, attending either "traditional" or "progressive" schools, were tested. Children's attribution of individual stimuli to the categories of men (M), women (F), or both sexes $(\mathrm{N})$ showed that personality attributes were categorized as either $\mathbf{M}$ or $\mathbf{F}$ more often than were behaviors. Younger children, those attending a progressive school, and girls categorized stimuli as $\mathbf{M}$ or $\mathbf{F}$ less often than did the other groups. Interactions between sex, age, and type of school were also observed. A comparison of 10-year-old Dutch and Italian children showed the latter to be more sex-stereotyped. Multidimensional scaling analyses of proximity matrices for separate subsets of the total sample enabled the detection of differences among groups for each set of stimuli, in terms of amount and type of clustering of stimuli in the resulting two-dimensional configurations. These results paralleled those obtained on the basis of the frequency data.
\end{abstract}

Gender, perhaps the single most important grounds for human categorization, represents a powerful script that all too often constrains individuals to behave in socially prescribed ways and triggers expectations about others' behaviors. From the "outside," the child is constantly instructed in, and reminded of, gender differentiation (e.g., by children's books, television programs, parents' and teachers' socialization practices). From the "inside," the child's very gender identity, as soon as it is even rudimentarily established, functions as a processing schema for the encoding and organization of new information (Bem, 1984). To the extent that the social world in which the child grows is sex-differentiated, the child's own conceptions and perception of sex differences will also be sex-marked.

The aim of this study was to investigate Dutch children's sex-role knowledge of personality and behavioral characteristics of men and women using measures that would permit detection of qualitative, structural differences among subject groups and age-related changes in beliefs while retaining the possibility of a reliable quantitative data analysis. Because this study was part of a crossnational comparison, the results will then be compared with those previously obtained with Italian children (Zammuner, 1982).

The hypotheses of this study were the following: (1) Children's perceptions of sex-related attributes are influenced by general processes of self-enhancement-that

The author wishes to thank Willem Heiser of the University of Leiden for his advice and help on the statistical analysis, the Experimental Psychology Unit of the Faculty of Social Sciences of the University of Leiden for its hospitality when this research was carried out, and E. Grummels and $\mathrm{P}$. Gho for administering the task to subjects and for their help with data coding and analysis. Correspondence should be addressed to V. L. Zammuner, Dipartimento di Psicologia dello Sviluppo e della Socializzazione, Via B. Pellegrino 26, Università degli Studi di Padova, 35137 Padua, Italy. is, children tend to attribute positive but not negative characteristics to themselves and to members of their sex. (2) This attributional process interacts with children's perception of which judgments others make concerning the characteristics of the sexes. As a consequence, to the extent possible given their sex-role knowledge, children are expected to express judgments that deemphasize links between positive traits and the opposite sex (by attributing such traits to their own sex or by categorizing them as descriptive of both sexes) and deemphasize links between negative characteristics and their own sex (by attributing them to the opposite sex or to both sexes). (3) Age, school atmosphere, and nationality may influence attributions. Younger children were expected to express beliefs more dependent upon variations in their experiential worldthat is, to show greater attribution variability (due to the lesser structuring of their knowledge) and to be less sexstereotyped (due to the lesser salience yet of sex roles). Children attending a "progressive" school were expected to be less stereotyped, irrespective of socioeconomic background, than children attending a "traditional" school. (4) Personality traits were expected to be more stereotyped than behavioral characteristics, because traits are perceived as basic and inherently stable, whereas behaviors are more variable and situationally specific.

\section{METHOD}

\section{Stimulus Material}

Two sets of stimuli were used, the first formed by 28 personality traits, the second by 28 behaviors. The latter were thought appropriate to depict certain sex-role characteristics. Most stimuli were related to typical masculine (M) and feminine (F) characteristics (see Figures 1 and 2; see Zammuner, 1982, for more details).

Subjects, Task, and Procedure

Two hundred nineteen Dutch children were tested. The subjects attended the 4 th grade ( 45 boys, 64 girls; mean age $=10.2$ years) and 
6th grade ( 54 boys, 57 girls; mean age $=12.4$ years) at four elementary schools, located in a midsize university town. According to gathered information relevant to sex-role conception, School 1 (located in a middle-upper-class area) and School 2 (in a middle-lower-class area) were "progressive"; School 3 (in a middle-class-area) and School 4 (in a middle-lower-class area) were "traditional."

Each stimulus word was presented to the children collectively in their classroom, in a randomized order. Traits were always presented first. The children were asked to judge whether each stimulus described men $(M)$, women $(F)$, or both sexes $(\mathrm{N})$; they marked each judgment on a sheet presenting the three categories. In general, the children enjoyed this attribution "game."

\section{Measures}

Data obtained using the two stimuli sets were first analyzed in terms of raw frequencies of attribution of each stimulus to each category. To account for the results in a more comprehensive way than was possible by referring to the frequency data alone, a measure of association was used. Pairwise frequencies were interpreted as "proximities," and their relation was explored via a multidimensional scaling (MDS) method. The proximity measure was the number of times stimulus $j$ was placed in the same category as stimulus $k$, regardless of the category in which it was placed. The INDSCAL model was used (Carroll \& Chang, 1970) to describe similarities and differences between groups; proximity matrices were formed for each male and female group (i.e., 16 in total). With INDSCAL, each proximity matrix is described in terms of one common configuration of stimuli, called group stimulus space, and a set of weights, one for each dimension of that space. Similarity between groups leads to identical positioning of points in the group stimulus space; differences show up in a differential weighting of axes. Several INDSCAL analyses on separate subsets of the groups were carried out, using the ALSCAL-3 program (Takane, Young, \& de Leeuw, 1977). This admittedly rather specific description of differences was preferred to the use of a possibly overrestrictive model.

\section{RESULTS}

\section{Main Quantitative Results}

Children's categorization of individual stimuli as descriptive of men $(M)$, women $(F)$, or both sexes $(N)$ showed, in general, low percentages of $M$ or $F$ attribution (Table 1). Older children expressed a differential judgment ( $M$ or $\mathbf{F})$ more often than did younger children for both behaviors and personality traits and for both $\mathrm{F}$ and $\mathrm{M}$ attributions. Results showed that 6th graders of School 1 (progressive) were the least sex-biased and the most homogeneous group; traditional 6th graders of both age groups were, on the contrary, the most sex-biased. In general, traits were judged $M$ or $F$ more often than behaviors by both age groups. The F categorization of traits was higher than the $M$ categorization for both sexes, at both ages, and showed higher intergroup variability.

Two stereotypical scores were computed to test some of the trends just reported. For each of the seven most extreme personality traits-namely, lazy, superficial, clever, absent-minded, loud, violent, and strong as $\mathrm{M}$, and patient, shy, sensitive, chatter-box, gossipy, vain, and weak as F-a score of 1 was assigned if the stimulus was "correctly" attributed (e.g., strong categorized as M); a score of 0 was assigned otherwise. Maximum individual $F$ and $M$ scores could thus be 7.0. An analysis of variance (ANOVA) ${ }^{1}$ showed that older children [age, $F(1,160)=5.37, p<.02]$ and "traditional" children [school type, $F(1,160)=24.58, p<.001$ ] stereotyped the sexes more than did younger and "progressive" children ( 4.0 vs. 3.5 and 4.3 vs. 3.3 , respectively), and that they stereotyped women more than men $[4.3$ vs. 3.4 ; stereotypical categorization, $F(1,160)=39.18, p<$ $.001]$. At 12 years of age, traditional children stereotyped the sexes more than did progressive children [age $X$ school type, $F(2,160)=24.0, p<.001]$; older children stereotyped women more than men [age $\times$ stereotypical categorization, $F(2,160)=7.12, p<.01]$; and traditional children stereotyped women more than did progressive children [school type $\times$ stereotypical categorization, $F(2,160)=2.19, p>.08]$. Finally, the greatest difference between the age groups was the higher $F$ stereotyping by 12 -year-olds (both boys and girls) (4.6) than by 10year-olds (3.8). Both sexes and both age groups stereotyped men roughly to the same extent (about 3.4) [age $\times$ stereotypical categorization $\times \operatorname{sex}, F(2,160)=5.38$, $p<.05]$. These quantitative results were further confirmed by the MDS analyses reported in the next section.

\section{A Structural Account}

To interpret MDS configurations in terms of regions, masculine, feminine, and neutral directional axes were drawn by hand on the basis of percentage data (e.g., according to which stimuli were attributed to either F, $M$, or $\mathrm{N}$ by $80 \%$ or more of all subjects; see Figures 1 and 2 ).

A first set of ALSCAL-3 analyses was performed on the total sample. The configuration obtained for personality traits (Figure 1) was rather unambiguous, because stimuli did not cluster in the center and distances between

Table 1

Dutch Children's Categorization of 28 Behaviors and 28 Personality Traits as Masculine and Feminine (Average Percentage Frequencies)

\begin{tabular}{|c|c|c|c|c|c|c|c|c|}
\hline & \multicolumn{4}{|c|}{ Girls } & \multicolumn{4}{|c|}{ Boys } \\
\hline & \multicolumn{2}{|c|}{ Progressive } & \multicolumn{2}{|c|}{ Traditional } & \multicolumn{2}{|c|}{ Progressive } & \multicolumn{2}{|c|}{ Traditional } \\
\hline & 10 years & 12 years & 10 years & 12 years & 10 years & 12 years & 10 years & 12 years \\
\hline \multicolumn{9}{|c|}{ Categorization of Stimuli as Masculine } \\
\hline $\begin{array}{l}\text { Behaviors } \\
\text { Traits }\end{array}$ & $\begin{array}{l}15 \\
14\end{array}$ & $\begin{array}{l}16 \\
12\end{array}$ & $\begin{array}{l}19 \\
17\end{array}$ & $\begin{array}{l}27 \\
24\end{array}$ & $\begin{array}{l}21 \\
23\end{array}$ & $\begin{array}{l}16 \\
19\end{array}$ & $\begin{array}{l}24 \\
22\end{array}$ & $\begin{array}{l}29 \\
30\end{array}$ \\
\hline \multicolumn{9}{|c|}{ Categorization of Stimuli as Feminine } \\
\hline $\begin{array}{l}\text { Behaviors } \\
\text { Traits }\end{array}$ & $\begin{array}{l}15 \\
23\end{array}$ & $\begin{array}{l}15 \\
23\end{array}$ & $\begin{array}{l}17 \\
28\end{array}$ & $\begin{array}{l}29 \\
41 \\
\end{array}$ & $\begin{array}{l}20 \\
27\end{array}$ & $\begin{array}{l}16 \\
24\end{array}$ & $\begin{array}{l}16 \\
31\end{array}$ & $\begin{array}{l}27 \\
37\end{array}$ \\
\hline
\end{tabular}

Note-Values expressed are the percentages of all stimuli. 
$M$ and $F$ stimuli were quite large. The $F$ extreme was represented by gossipy, vain, chatterbox, tidy, and shy. Strong, noisy, lazy, violent, and absent-minded formed the M extreme. Closest to the $\mathbf{N}$, or sex-neutral, region were altruistic, generous, and wholehearted. Stimuli denoting qualities relevant for interpersonal relations (e.g., likable, sincere, loyal, and affectionate) clustered in the $\mathrm{F}$ region (i.e., between the $\mathrm{N}$ and $\mathrm{F}$ direction axes); those descriptive of cognitive qualities (e.g., clever, interesting, and intelligent) were located in the $\mathrm{M}$ region.

The total sample configuration of behaviors (Figure 2) and related groups' weights (not shown) on the two dimensions reflected instead a strong intergroup heterogeneity. Many stimuli clustered in the center and in between the $F$ and $M$ axes (i.e., stimuli were categorized by different subjects both as $\mathbf{M}$ and F). To construct and to repair formed the $\mathrm{M}$ extreme; to cure and to comfort formed the $\mathrm{F}$ extreme.

The age variable. The configurations obtained for each age group showed clear intergroup differences. For 6th graders (see Figure 11.1, in Zammuner, 1987), most traits fell in three large clusters, while for 4th graders, $M$ and $\mathrm{F}$ axes were located at opposite points in space, and stimuli spread much, forming a few small clusters (groups' weights confirmed the differences between "progressive" and "traditional" children and the greater heterogeneity of 4 th graders).

While for 4th graders many behaviors were part of one of two clusters close to the $\mathbf{N}$ axis (i.e., their categorization had been inconsistent), for 6th graders many stimuli were categorized as $\mathrm{M}$ or $\mathrm{F}$ and most fell on a horseshoeshaped continuum. Naturally enough, individual stimuli changed their location in space quite drastically for different subject groups (e.g., to serve was an extreme F action for 4th graders only, while to protect was very descriptive of men for 6th graders only).

The sex variable. Differences between boys and girls were shown by ASCAL-3 analyses. The traits configu-

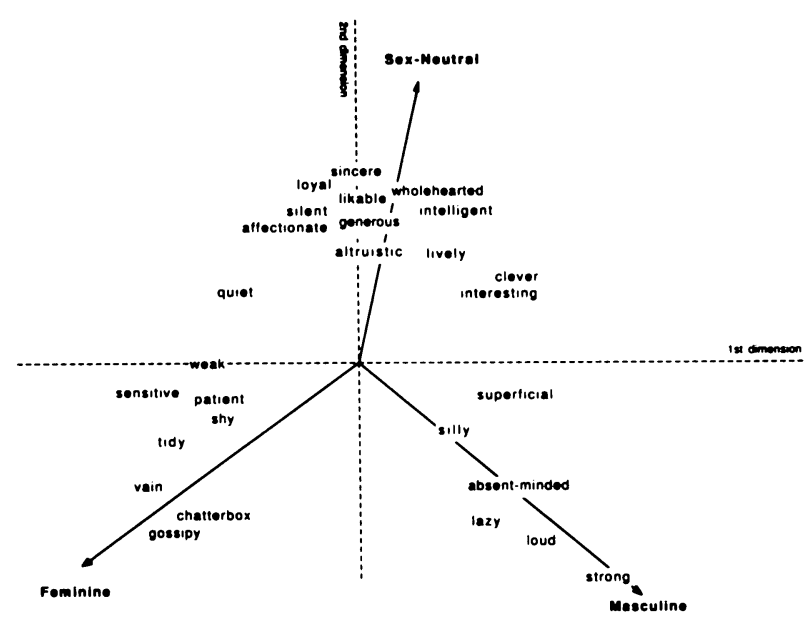

Figure 1. Ten- and 12-year-old Dutch children's categorization of 28 personality traits as descriptive of women, men, or both sexes (ALSCAL-3 two-dimensional configuration).

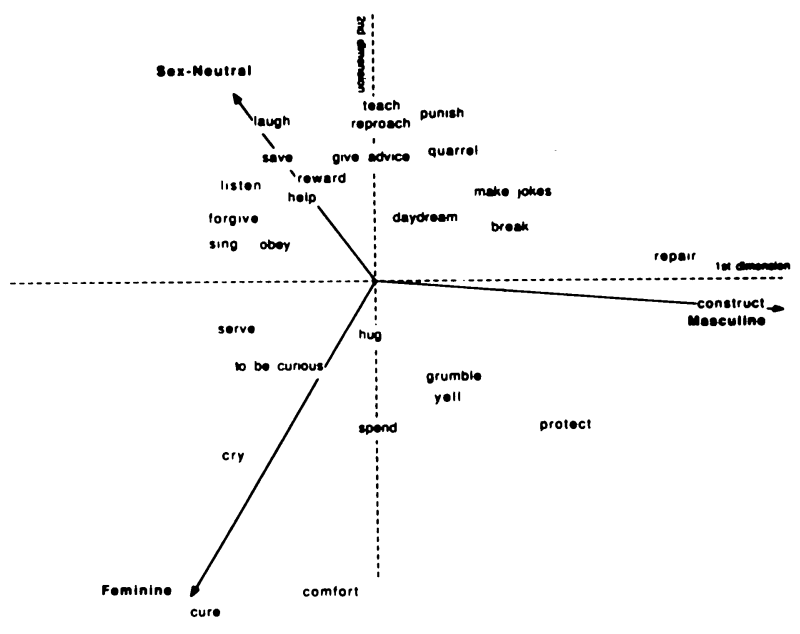

Figure 2. Ten- and 12-year-old Dutch children's categorization of 28 behaviors as descriptive of women, men, or both sexes (ALSCAL-3 two-dimensional configuration).

rations showed that attributions within each sex were rather homogeneous. The girls' configuration presented three large clusters; the stimuli location indicated both a small intergroup variability and a clear differentiation of stimuli: 12 traits were categorized as $\mathrm{N}, 9$ as F, and 7 as $\mathbf{M}$. The boys' showed greater judgment variability (stimuli formed looser clusters and often lay in the center) and an overall stronger $M / F$ differentiation. Individual stimuli were often judged as hypothesized by the selfenhancement principle (e.g., patient, sensitive, shy, and quiet as $\mathrm{F}$ by girls but as $\mathrm{N}$ by boys; interesting and clever as $\mathbf{N}$ by girls but as $\mathrm{M}$ by boys).

The sexes differed even more in their judgment of behaviors, and intergroup variability was greater. For girls, most stimuli fell in two large N-F and N-M clusters, contrary to boys (see Figure 11.2, in Zammuner, 1987).

Interaction of the age and sex variables. The comparison between 4th- and 6th-grade girls' configurations of traits showed most dramatically the interaction effects. The 4thgrade girls' most closely approached a perfect horseshoeshaped continuum (the boys' showed more clustering). For 6th-grade girls, stimuli fell in three compact M, F, and N clusters (the 6th-grade boys' clusters were looser; a few traits had been judged both $M$ and $F$, similar to those of 4th-grade boys'). For both sexes, the same-sex cluster was the least compact, indicating ambivalence in the attribution of stereotyped personality traits to the same sex.

Fourth-grade girls, especially progressive ones, categorized very few behaviors as $\mathrm{F}$ or $\mathrm{M}$ : most stimuli formed a large $\mathrm{N}$ cluster. In the 4th-grade boys' configuration, clear and large $M$ and $F$ clusters were present. The configurations of behaviors of 6th-grade boys and girls showed a pattern similar to that observed for traits, though with less well defined clusters. To cure, to comfort, and to cry were extreme F behaviors for both sexes; the boys' configuration showed two other F clusters comprising stimuli categorized as $\mathrm{N}$ by girls. Both sexes often categorized to punish, to break, to make jokes, to construct, and to repair as $\mathrm{M}$, but 
girls often judged them as N. In general, progressive children expressed the least stereotyped categorization.

\section{Dutch and Italian Children: Are There Differences?}

As noted earlier, this study was planned as part of a cross-national comparison. Results pertaining to Dutch and Italian 10-year-olds' categorization of 28 traits (for Italians, cf. Zammuner, 1982) were compared in an ANOVA. The results showed that Italian children were more stereotyped than the Dutch [15.7 traits vs. 13.2 were differentially categorized; nation, $F(1,184)=9.70, p<$ $.01]$, and boys were more so than girls [15.2 vs. 13.3; sex, $F(1,184)=3.17, p<.07]$; women were stereotyped more than men [7.6 vs. 6.9 traits; stereotypical categorization, $F(1,184)=5.21, p<.05$ ]. Italian children stereotyped men (but not women) more than did the Dutch [8.4 vs. 5.4; nation by categorization, $F(2,184)=42.21$, $p<.001$ ]; boys stereotyped men (but not women) more than they did girls [sex $\times$ categorization, $F(2,184)=$ $9.45, p<.01]$; finally, mainly "traditional" children stereotyped women more than they did men $[8.0$ vs. 6.9 ; school type $\times$ categorization, $F(2,184)=2.67, p<.10$ ]

\section{DISCUSSION}

The results obtained confirmed the hypotheses and showed how the posited effects interacted with each other:

1. Girls of both age groups (and of both countries) differentiate stimuli according to sex less often than do boys and display greater intergroup variability.

2. Behaviors, contrary to Williams, Bennett, and Best's (1975) hypothesis that stimuli with clear behavioral connotations are learned earlier, are generally less stereotyped than are personality traits, possibly because the latter are seen as more stable individual characteristics. Indeed, much of children's socialization to sex roles occurs via linguistic labels that typically define traits rather than behaviors (e.g., as when someone says, "She is such a sweet girl!" or "What a brave boy!").

3. Older children stereotype the sexes more than do younger ones, because their knowledge of sex roles is greater and because sex-role options become more salient with the increase in age.

4. At both ages, however, women are stereotyped more than men, and more for personality traits than for behaviors. Similar results were obtained with Italian children (with the same stimuli; Zammuner, 1982), and with Brazilian children (Tarrier \& Gomes, 1981, with stimuli developed by Williams et al., 1975). The present results also show a greater heterogeneity in boys' and girls' categorization of behaviors than of traits, and stronger sex differences in the stereotyping of men (less by girls), than of women. Altogether, such results contradict the finding (Best et al., 1977) that male traits are better known by both sexes. The greater knowledge, and stereotyping, of the female scx by both boys and girls might be due to the fact that women (as mothers, teachers, etc.) represent the model most easily and frequently available for young children. In contraposition, male models are less available, and boys are motivated more than girls to pay attention to characteristics of their own sex. These results thus showed that Dutch, Italian, and Brazilian children are less sexstereotyped and have sex-role knowledge that is different from that of British, American, and Irish children. These cultural differences, needless to say, ought to be further investigated.

5. Cognitive processes of same-group enhancement and opposite-group devaluation influence the categorization of traits and behaviors (e.g., the attribution of such negative and positive traits as silly, lazy, clever, intelligent, gossipy, weak, and vain). However, boys seem to be more biased in this respect than girls (remember that boys attribute more stimuli to men than girls do). A tentative conclusion, supported also by similar results obtained in studies of children's preferences for toys (Zammuner, 1981,1988 ), is that girls tend to expand their role possibilities by categorizing fewer items, if they are positive and traditionally associated with the opposite sex, as typical of men (e.g., intelligent), or as typical of women if they are negative and associated with their own sex (e.g., weak).

6. Finally, this study confirms both the influence of models and values the child can observe daily (the school atmosphere) and the impact of general cultural attitudes toward sex roles, that is, the general greater stereotyping of sex roles by Italian children (see Zammuner, 1981, 1982, 1987, 1988 ) and their greater judgment variability in comparison with that of Dutch children. The latter result might reflect a lesser homogeneity of sex-role concepts in the Italian culture, due to a transition state from traditional and rigid definitions of sex roles to more flexible and varied ones.

To conclude, the results show that it is useful to study the structure and content of sex-role conceptions rather than their sheer amount, and point out that in such studies we need to consider the effects of processes that reflect a search for social acceptance and ego-maintaining biases.

\section{REFERENCES}

BEM, S. (1984). Androgyny and gender schema theory: A conceptual and empirical integration. In T. B. Sonderegger (Ed.), Nebraska Symposium on Motivation: Psychology and gender (pp. 179-226). Lincoln: University of Nebraska Press.

Best, D. L., Williams, J. E., Cloud, J. M., Davis, S. W., RobertSON, L. S., Edwards, J. R., Giles, H., \& Fowles, J. (1977). Development of sex-trait stereotypes among young children in the United States, England, and Ireland. Child Development, 48, 806-819.

Carroll, J. D., \& Chang, J. J. (1970). Analysis of individual differences in multidimensional scaling via an $\mathrm{N}$-way generalization of “Eckart-Young"' decomposition. Psychometrica, 35, 283-319.

TaKane, Y., Young, F. W., De Leeuw, J. (1977). Nonmetric individual differences multidimensional scaling: An alternating least squares method with optimal scaling features. Psychometrica, 42, 7-67.

TARRIER, N., \& Gomes, L. F. (1981). Knowledge of sex-trait stereotypes. Effects of age, sex and social class on Brazilian children. Journal of Cross-Cultural Psychology, 12, 81-93.

Williams, J., BennetT, S. M., \& Best, D. L. (1975). Awareness and expression of sex stereotypes in young children. Developmental Psychology, 11, 635-642.

ZAMMUNER, V. L. (1981). Le preferenze dei bambini rispetto ai ruoli sessuali: Una verifica empirica. Età Evolutiva, 9, 38-52.

ZAMmUNER, V. L. (1982). Sex role stereotypes in Italian children. International Journal of Psychology, 17, 43-63.

Zammuner, V. L. (1987). Children's sex role stereotypes. In P. Shaver \& C. Hendrick (Eds.), Review of personality and social psychology: Vol. 7. Sex and gender (pp. 272-293). New York: Sage.

ZAmmuner, V. L. (1988). Conoscenze e preferenze rispetto al ruolo sessuale: Una ricerca con bambini e adulti olandesi. Età Evolutiva, 31, 48-61.

\section{NOTE}

1. To have equal cells, only the first 21 children listed in each group were considered in this analysis. A further ANOVA, carried out on all children's scores, but irrespective of children's sex, confirmed the reported results. 